\title{
Infrared and Raman Spectra of $\mathrm{C}_{4} \mathrm{H}_{4} \mathrm{Se}$ and $\mathrm{C}_{4} \mathrm{D}_{4} \mathrm{Se}$ Isotopomers: A DFT-PT2 Anharmonic Study
}

\author{
Andrea Alparone \\ Department of Chemistry, University of Catania, Viale A. Doria 6, 95125 Catania, Italy \\ Correspondence should be addressed to Andrea Alparone; agalparone@gmail.com
}

Received 7 May 2013; Accepted 1 July 2013

Academic Editor: James W. Gauld

Copyright (C) 2013 Andrea Alparone. This is an open access article distributed under the Creative Commons Attribution License, which permits unrestricted use, distribution, and reproduction in any medium, provided the original work is properly cited.

\begin{abstract}
IR and Raman spectra of selenophene and of its perdeuterated isotopomer have been obtained in gas phase through densityfunctional theory (DFT) computations. Vibrational wavenumbers have been calculated using harmonic and anharmonic secondorder perturbation theory (PT2) procedures with the B3LYP method and the 6-311G ${ }^{* *}$ basis set. Anharmonic overtones have been determined by means of the PT2 method. The introduction of anharmonic terms decreases the harmonic wavenumbers, giving a significantly better agreement with the experimental data. The most significant anharmonic effects occur for the C- $\mathrm{H}$ and $\mathrm{C}-$ D stretching modes, the observed H/D isotopic wavenumber redshifts being satisfactorily reproduced by the PT2 computations within $6-20 \mathrm{~cm}^{-1}(1-3 \%)$. In the spectral region between $500 \mathrm{~cm}^{-1}$ and $1500 \mathrm{~cm}^{-1}$, the IR spectra are dominated by the out-ofplane $\mathrm{C}-\mathrm{H}(\mathrm{C}-\mathrm{D})$ bending transition, whereas the Raman spectra are mainly characterized by a strong peak mainly attributed to the $\mathrm{C}=\mathrm{C}+\mathrm{C}-\mathrm{C}$ bonds stretching vibration with the contribution of the in-plane $\mathrm{C}-\mathrm{H}(\mathrm{C}-\mathrm{D})$ bending deformation. The current results confirm that the PT2 approach combined with the B3LYP/6-311G ${ }^{* *}$ level of calculation is a satisfactory choice for predicting vibrational spectra of cyclic molecules.
\end{abstract}

\section{Introduction}

Calculated harmonic vibrational wavenumbers of organic compounds typically deviate from experimental fundamental data, especially overestimating observed wavenumbers of high-energy $\mathrm{X}-\mathrm{H}(\mathrm{X}=\mathrm{C}, \mathrm{O}, \mathrm{N})$ stretches [1]. Two principal procedures can be employed in practice to correct the shortcomings of the harmonic approximation: (1) scaling methods [2,3] and (2) anharmonic computations [4-7]. Scaling factors are usually derived for a certain level of theory and basis set by fitting computed harmonic frequencies to experimental data for restricted subsets of molecules. Scaling corrections often work adequately, even if there are specific cases for which scaling factor transferability could originate questionable results $[8,9]$. A much more rigorous treatment is furnished by anharmonic computations that are commonly performed through perturbative [4-6] or variational [7] methods. Anharmonic perturbative approaches are generally proven to be less accurate than variational schemes [10], although they are particularly reliable for predicting fundamental wavenumbers of semirigid cyclic compounds [10-17].
In this contribution we report some interesting results on the performances of the anharmonic second-order perturbation theory (PT2) [6] as implemented in the GAUSSIAN 09 program [18] to predict vibrational wavenumbers. We have chosen to study selenophene $\left(\mathrm{C}_{4} \mathrm{H}_{4} \mathrm{Se}\right)$ and its perdeuterated isotopomer $\left(\mathrm{C}_{4} \mathrm{D}_{4} \mathrm{Se}\right)$, for which experimental vibrational spectra with complete assignments of all the transitions are available from the literature [19-23]. Theoretically, the vibrational spectra of selenophene were previously computed at ab initio and density-functional theory (DFT) methods under the harmonic approximation [24-27]. In the present study we have used the hybrid functional B3LYP $[28,29]$ with the fairly flexible 6-311 $\mathrm{G}^{* *}$ basis set [1]. Anharmonic PT2 B3LYP/6-311G ${ }^{* *}$ calculations have been recently performed with success on naphthalene, reproducing accurately the experimental wavenumbers [16]. Overtone wavenumbers of $\mathrm{C}_{4} \mathrm{H}_{4} \mathrm{Se}$ and $\mathrm{C}_{4} \mathrm{D}_{4}$ Se have been here predicted for the first time. We also will discuss briefly the most intense vibrational transitions of the IR and Raman spectra. Selenophene which is homologue of the furan molecule has long been the subject of many experimental and theoretical studies as promising 
TABLE 1: Structural parameters of $\mathrm{C}_{4} \mathrm{H}_{4}$ Se and $\mathrm{C}_{4} \mathrm{D}_{4} \mathrm{Se}^{\mathrm{a}}$.

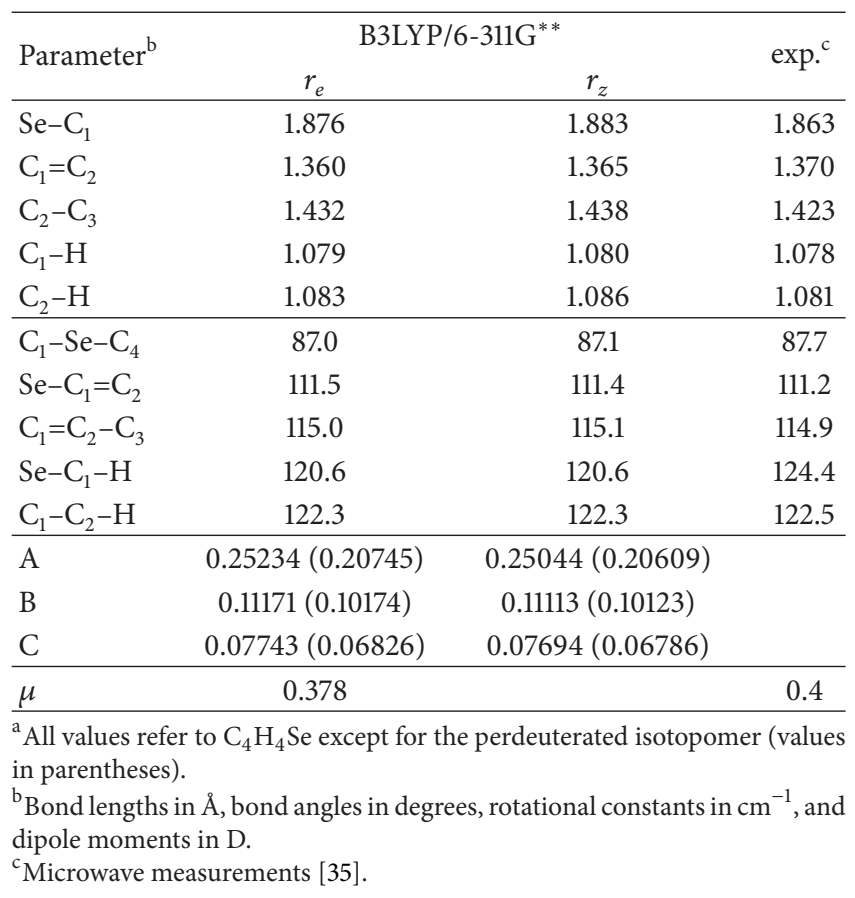

building block of $\pi$-conjugated polymers for nonlinear optical applications [27, 30-34].

\section{Computational Details}

All calculations were carried out with the GAUSSIAN 09 package. Geometry of selenophene was fully optimized under the $\mathrm{C}_{2 v}$ point group symmetry using the B3LYP functional with the $6-311 \mathrm{G}^{* *}$ basis set. The harmonic frequencies of selenophene and its perdeuterated isotopomer were obtained using an analytical procedure. The anharmonic corrections to wavenumbers were computed through the PT2 treatment. The PT2 procedure in combination with DFT methods is proven to be adequate to predict anharmonic vibrational wavenumbers of cyclic compounds [10-17], including the homologues furan $[10,13]$ and thiophene [10]. Under the PT2 approximation, third and semidiagonal fourth energy derivatives with respect to normal coordinates were determined using a numerical differentiation scheme implemented in GAUSSIAN 09. Specifically, we used a step-size displacement of $0.025 \AA$ along the normal coordinate as usually adopted in the literature [12-14]. Fundamental frequencies $\left(v_{i}\right)$ were obtained from harmonic $\left(\omega_{i}\right)$, diagonal $\left(\chi_{i i}\right)$, and off-diagonal $\left(\chi_{i j}\right)$ anharmonic constant values as [6]:

$$
v_{i}=\omega_{i}+2 \chi_{i i}+\frac{1}{2} \sum_{j \neq i} \chi_{i j}
$$

Besides the PT2 approach, as commonly adopted in the literature, we corrected the computed harmonic wavenumbers by using a scaling factor previously determined by Irikura et al. [36] through a least-mean-squared fitting procedure between 3310 experimental and calculated wavenumbers. In the specific case of the B3LYP/6-311G ${ }^{* *}$ level,

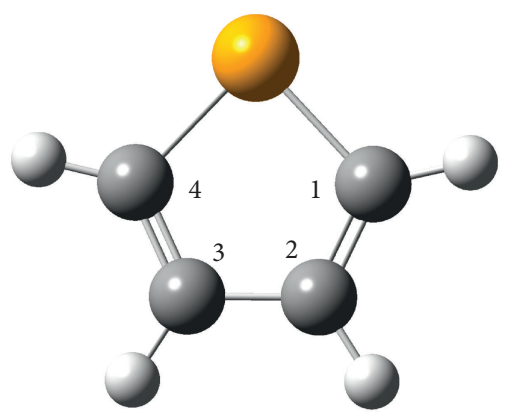

FIgURE 1: Atom numbering for selenophene.

the scaling factor is 0.9669 . The assignments of the vibrational transitions were obtained on the basis of normal modes, as displacements in redundant internal coordinates (in GAUSSIAN 09, option Freq $=$ IntModes) and also through the visualization software Chemcraft [37].

\section{Result and Discussion}

3.1. Geometry, Rotational Constants, and Dipole Moment. The computed bond lengths, angles, and dipole moment $(\mu)$ of selenophene (Figure 1) are listed in Table 1, together with the gas phase experimental data for comparison [35]. The B3LYP/6-311G ${ }^{* *}$ geometry agree reasonably well with experiment, with a root mean square (rms) deviation $\left\{\mathrm{rms}=\left[(1 / n) \sum_{i}^{n}\left(x_{i}^{\text {exp. }}-x_{i}^{\text {calc. }}\right)^{2}\right]^{1 / 2}\right\}$ where $x_{i}$ is a geometrical parameter value for the bond lengths of $0.008 \AA$ and for bond angles of $1.7^{\circ}$. In Table 1 the vibrationally averaged geometries $\left(r_{z}\right.$ structure) determined using vibrationrotation interaction constant computations [6] are also reported. As can be appreciated from the data in the table, the inclusion of vibrational averaging corrections increases the bond lengths by $0.001-0.007 \AA$, whereas the bond angles deviate within $0.1^{\circ}$. Table 1 also includes rotational constants (A, B, and C) for $\mathrm{C}_{4} \mathrm{H}_{4} \mathrm{Se}$ and $\mathrm{C}_{4} \mathrm{D}_{4} \mathrm{Se}$. The results show that the vibrational averaging corrections little affect the rotational constants which are much more dependent on the H/D isotopic effects, with the values of $\mathrm{C}_{4} \mathrm{D}_{4}$ Se being decreased by ca. $20 \%$ with respect to those of $\mathrm{C}_{4} \mathrm{H}_{4} \mathrm{Se}$.

The dipole moment is directed along the $\mathrm{C}_{2}$ symmetry axis and is here calculated at $0.378 \mathrm{D}$, in good agreement with the experimental datum of $0.4 \mathrm{D}$ [35] and previous theoretical estimates $[25,30]$.

3.2. Vibrational Spectra of $\mathrm{C}_{4} \mathrm{H}_{4} \mathrm{Se}$ and $\mathrm{C}_{4} \mathrm{D}_{4} \mathrm{Se}$. Experimentally IR and Raman spectra of selenophene were previously investigated by Cataliotti and coworkers [19-23]. Some of theoretical studies restricted to $\mathrm{C}_{4} \mathrm{H}_{4} \mathrm{Se}$ were previously carried out under the harmonic approximation [24-27]. To the best of our knowledge anharmonic vibrational wavenumbers of fundamentals and overtones of selenophene and of its perdeuterated isotopomer are lacking to date. Tables 2 and 3 collect the B3LYP/6-311G ${ }^{* *}$ harmonic and anharmonic wavenumbers $\left(\omega\right.$ and $\nu$ ), IR intensities $\left(I_{\mathrm{IR}}\right)$, and Raman activities $\left(A_{\text {Raman }}\right)$ of $\mathrm{C}_{4} \mathrm{H}_{4} \mathrm{Se}$ and $\mathrm{C}_{4} \mathrm{D}_{4} \mathrm{Se}$. These tables 
TABLE 2: Vibrational harmonic, $\omega$, and anharmonic, $v$, wavenumbers $\left(\mathrm{cm}^{-1}\right)$, infrared intensities, $I_{\mathrm{IR}}(\mathrm{km} / \mathrm{mol})$, and Raman activities $A_{\text {Raman }}$ $\left(\AA^{4} / \mathrm{amu}\right)$ of $\mathrm{C}_{4} \mathrm{H}_{4}$ Se.

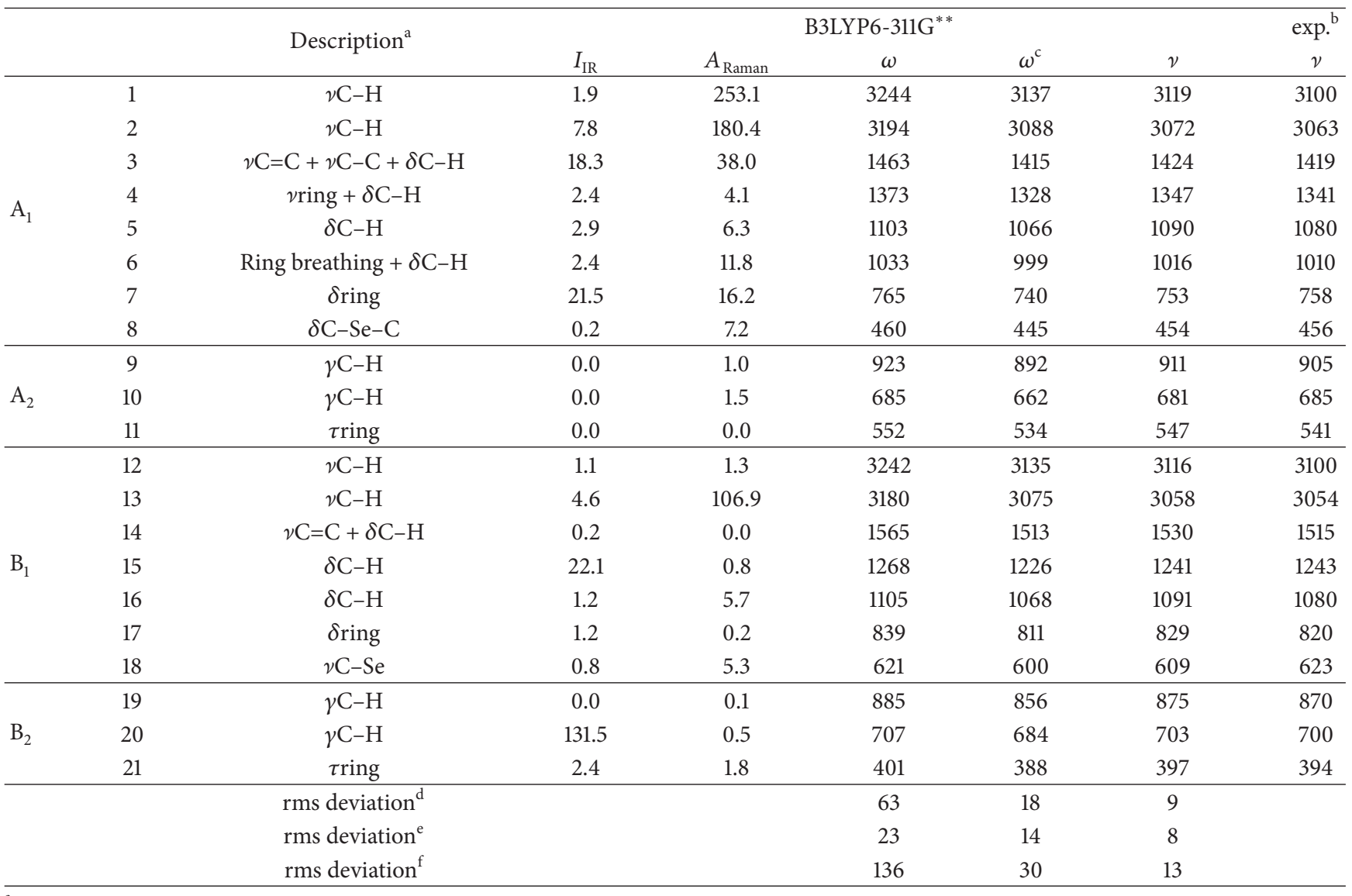

${ }^{a} \nu$ : stretching; $\delta$ : in-plane bending, $\gamma$ : out-of-plane bending, $\tau$ : torsion.

${ }^{\mathrm{b}}$ Reference [21].

${ }^{\mathrm{c}}$ Scaled harmonic wavenumbers. The scaling factor of 0.9669 was taken from Irikura et al. [36]

${ }^{\mathrm{d}}$ All the vibrational modes.

${ }^{\mathrm{e}}$ All the vibrational modes excluding the $\nu \mathrm{C}-\mathrm{H}$ modes.

f $\nu \mathrm{C}-\mathrm{H}$ modes.

also include the available experimental data [21-23] for comparison. Selenophene belongs to the $\mathrm{C}_{2 v}$ symmetry point group with 21 normal modes classified as $8 \mathrm{~A}_{1}+3 \mathrm{~A}_{2}+7 \mathrm{~B}_{1}+3 \mathrm{~B}_{2}$, with all except for the $A_{2}$ modes being IR active. The present assignments of the vibrational modes are in good agreement with both experimental [21-23] and previous theoretical investigations [24-27].

In Figures 2 and 3 we plot the percentage deviations $\left(\left(\left(\omega_{i}^{\text {calc. }}-\omega_{i}^{\text {exp }}\right) /\left(\omega_{i}^{\text {exp } ~}\right)\right) \times 100\right)$ of the B3LYP/6-311G ${ }^{* *}$ harmonic and anharmonic vibrational wavenumber values from the experimental data of $\mathrm{C}_{4} \mathrm{H}_{4} \mathrm{Se}$ and $\mathrm{C}_{4} \mathrm{D}_{4} \mathrm{Se}$, respectively. Not surprisingly, the harmonic wavenumbers of $\mathrm{C}_{4} \mathrm{H}_{4} \mathrm{Se}$ and $\mathrm{C}_{4} \mathrm{D}_{4}$ Se systematically overestimate the experimental values: in fact the percentage deviations from the observed data are within $4.6 \%$ and $6.5 \%$, respectively, whereas the rms deviations for all the modes are calculated to be 63 and $38 \mathrm{~cm}^{-1}$, respectively. When excluding the $\mathrm{C}-\mathrm{H}$ stretches $(\nu \mathrm{C}-\mathrm{H})$, these rms deviations are reduced to $23 \mathrm{~cm}^{-1}$ and $22 \mathrm{~cm}^{-1}$, respectively. For $\mathrm{C}_{4} \mathrm{H}_{4} \mathrm{Se}$, when the harmonic wavenumbers are corrected by the scaling factor of 0.9669 , the rms deviation for all the modes decreases to $18 \mathrm{~cm}^{-1}$, whereas the percentage deviations from the experimental data are within $3.7 \%$. As can be appreciated from Figures 2 and 3, in comparison to both the harmonic and scaled harmonic values, the anharmonic wavenumbers are in better agreement with experiment (with the exceptions of mode no. 10 for $\mathrm{C}_{4} \mathrm{H}_{4} \mathrm{Se}$ and modes no. is 11 and 18 for $\mathrm{C}_{4} \mathrm{D}_{4} \mathrm{Se}$, which are better reproduced by the harmonic computations), with a percentage error within $2.2 \%$ for $\mathrm{C}_{4} \mathrm{H}_{4} \mathrm{Se}$ and $5.3 \%$ for $\mathrm{C}_{4} \mathrm{D}_{4} \mathrm{Se}$. In line with previous results found for other cyclic compounds [10-17], the most significant anharmonic corrections occur for the $\nu \mathrm{C}-\mathrm{H}$ vibrations, which reduce the harmonic wavenumber values by $122-126 \mathrm{~cm}^{-1}$ (ca. $-4 \%$ ), improving noticeably the agreement with the experimental data (within $4-19 \mathrm{~cm}^{-1}, 0.1-0.6 \%$ ). It is worth noting that, for a certain ith $\mathrm{C}-\mathrm{H}$ (or $\mathrm{C}-\mathrm{D}$ ) stretching mode, the largest vibrational anharmonic constants $\left(\chi_{i, j}\right)$ involve the remaining $\mathrm{C}-\mathrm{H}$ (or $\mathrm{C}-\mathrm{D}$ ) stretches as well as the diagonal term. In Figure 4 we report the calculated $\chi_{i, j}(i=1$, $j=1-21$ ) values for mode no. 1 , taken as an example. The results show that the most significant contribution originates 
TABLE 3: Vibrational harmonic, $\omega$, and anharmonic, $v$, wavenumbers $\left(\mathrm{cm}^{-1}\right)$, infrared intensities, $I_{\mathrm{IR}}(\mathrm{km} / \mathrm{mol})$, and Raman activities $A_{\text {Raman }}$ $\left(\AA^{4} / \mathrm{amu}\right)$ of $\mathrm{C}_{4} \mathrm{D}_{4} \mathrm{Se}$.

\begin{tabular}{|c|c|c|c|c|c|c|c|}
\hline & & Deccrintion ${ }^{a}$ & & & & & exp. ${ }^{b}$ \\
\hline & & Description & $I_{\text {IR }}$ & $A_{\text {Raman }}$ & $\omega$ & $v$ & $v$ \\
\hline & 1 & $\nu \mathrm{C}-\mathrm{D}$ & 1.4 & 115.3 & 2409 & 2334 & 2335 \\
\hline & 2 & $\nu \mathrm{C}-\mathrm{D}$ & 1.7 & 68.6 & 2360 & 2283 & 2280 \\
\hline & 3 & $\nu \mathrm{C}=\mathrm{C}+\nu \mathrm{C}-\mathrm{C}+\delta \mathrm{C}-\mathrm{D}$ & 21.4 & 40.4 & 1436 & 1403 & 1398 \\
\hline A & 4 & $\nu$ ring $+\delta \mathrm{C}-\mathrm{D}$ & 4.9 & 6.8 & 1239 & 1215 & 1210 \\
\hline$A_{1}$ & 5 & Ring breathing $+\delta \mathrm{C}-\mathrm{D}$ & 1.0 & 19.7 & 863 & 849 & 847 \\
\hline & 6 & $\delta \mathrm{C}-\mathrm{D}$ & 1.0 & 4.9 & 788 & 781 & 774 \\
\hline & 7 & $\delta$ ring & 16.4 & 7.6 & 691 & 682 & 683 \\
\hline & 8 & $\delta \mathrm{C}-\mathrm{Se}-\mathrm{C}$ & 0.3 & 6.6 & 446 & 441 & 444 \\
\hline & 9 & $\gamma \mathrm{C}-\mathrm{D}$ & 0.0 & 0.8 & 766 & 757 & 748 \\
\hline $\mathrm{A}_{2}$ & 10 & $\gamma \mathrm{C}-\mathrm{D}$ & 0.0 & 0.0 & 532 & 527 & 528 \\
\hline & 11 & $\tau$ ring & 0.0 & 0.0 & 473 & 469 & 475 \\
\hline & 12 & $\nu \mathrm{C}-\mathrm{D}$ & 0.3 & 0.1 & 2402 & 2335 & 2335 \\
\hline & 13 & $\nu \mathrm{C}-\mathrm{D}$ & 1.8 & 54.1 & 2344 & 2264 & 2267 \\
\hline & 14 & $\nu \mathrm{C}=\mathrm{C}+\delta \mathrm{C}-\mathrm{D}$ & 2.1 & 0.0 & 1506 & 1475 & 1460 \\
\hline $\mathrm{B}_{1}$ & 15 & $\delta \mathrm{C}-\mathrm{D}+\nu \mathrm{C}-\mathrm{Se}$ & 8.9 & 0.4 & 1018 & 994 & 1001 \\
\hline & 16 & $\delta$ ring $+\delta \mathrm{C}-\mathrm{D}$ & 3.3 & 4.3 & 858 & 849 & 806 \\
\hline & 17 & $\delta \mathrm{C}-\mathrm{D}$ & 0.1 & 0.1 & 733 & 726 & 718 \\
\hline & 18 & $\nu \mathrm{C}-\mathrm{Se}$ & 1.4 & 4.8 & 588 & 578 & 592 \\
\hline & 19 & $\gamma \mathrm{C}-\mathrm{D}$ & 0.2 & 0.2 & 694 & 687 & 690 \\
\hline $\mathrm{B}_{2}$ & 20 & $\gamma \mathrm{C}-\mathrm{D}$ & 74.9 & 0.1 & 525 & 522 & 520 \\
\hline & 21 & $\tau$ ring & 0.5 & 1.1 & 366 & 363 & 362 \\
\hline & & rms deviation $^{c}$ & & & 38 & 11 & \\
\hline & & rms deviation $^{\mathrm{d}}$ & & & 22 & 12 & \\
\hline & & rms deviation $^{\mathrm{e}}$ & & & 75 & 2 & \\
\hline
\end{tabular}

${ }^{a} \nu$ : stretching; $\delta$ : in-plane bending, $\gamma$ : out-of-plane bending, $\tau$ : torsion.

${ }^{\mathrm{b}}$ References [22, 23].

${ }^{c}$ All the vibrational modes.

${ }^{\mathrm{d}}$ All the vibrational modes excluding the $\nu \mathrm{C}-\mathrm{H}$ modes.

${ }^{\mathrm{e}} \nu \mathrm{C}-\mathrm{H}$ modes.

from the coupling with the mode no. 15, with the $\chi_{1,15}$ value being calculated to be $-108 \mathrm{~cm}^{-1}$ for $\mathrm{C}_{4} \mathrm{H}_{4} \mathrm{Se}$ and $-47 \mathrm{~cm}^{-1}$ for $\mathrm{C}_{4} \mathrm{D}_{4} \mathrm{Se}$. Through (1), these anharmonic terms determine ca. $90 \%\left(\mathrm{C}_{4} \mathrm{H}_{4} \mathrm{Se}\right)$ and $60 \%\left(\mathrm{C}_{4} \mathrm{D}_{4} \mathrm{Se}\right)$ of the total anharmonic corrections. Thus, on going from the harmonic to the anharmonic data of $\mathrm{C}_{4} \mathrm{H}_{4} \mathrm{Se}$, the rms deviation from the observed values for all the modes is decreased by ca. one order of magnitude (from 63 to $9 \mathrm{~cm}^{-1}$ ). Note that for the perdeuterated isotopomer the rms deviations are much more closer to each other, being $38 \mathrm{~cm}^{-1}$ for the harmonic and $11 \mathrm{~cm}^{-1}$ for the anharmonic values.

The high-energy IR and Raman spectral regions for $\mathrm{C}_{4} \mathrm{H}_{4} \mathrm{Se}\left(\mathrm{C}_{4} \mathrm{D}_{4} \mathrm{Se}\right)$ are exclusively characterized by the $\nu \mathrm{C}-$ $\mathrm{H}(\nu \mathrm{C}-\mathrm{D})$ peaks, predicted in the $3058-3119 \mathrm{~cm}^{-1}$ (2264$\left.2335 \mathrm{~cm}^{-1}\right)$ wavenumber range by the anharmonic computations, in good agreement with experiment [21-23]. Figures 5 and 6 display the anharmonic B3LYP/6-311G** vibrational spectra in the $1500-500 \mathrm{~cm}^{-1}$ wavenumber range for $\mathrm{C}_{4} \mathrm{H}_{4} \mathrm{Se}$ and $\mathrm{C}_{4} \mathrm{D}_{4} \mathrm{Se}$, respectively. The spectral profiles were constructed with pure Lorentzian band shapes with a full width at half maximum of $10 \mathrm{~cm}^{-1}$. In these figures we also show graphical representations of the atomic displacement vectors of the most interesting vibrations. As can be appreciated from Figure 5, the IR spectrum of $\mathrm{C}_{4} \mathrm{H}_{4} \mathrm{Se}$ is dominated by an absorption $\left(I_{\text {IR }}=131.5 \mathrm{~km} / \mathrm{mol}\right)$ located at $703 \mathrm{~cm}^{-1}$ (707 and $684 \mathrm{~cm}^{-1}$ under the harmonic and scaled harmonic approximation, resp.). This mode is attributed to a pure outof-plane $\mathrm{C}-\mathrm{H}$ bending deformation. It is worth noting that the anharmonic calculations are in satisfactory agreement with experiment, which gives a very strong peak at $700 \mathrm{~cm}^{-1}$ $(0.4 \%)$. The corresponding absorption in the calculated spectrum of the perdeuterated isotopomer (Figure 6) is placed at $522 \mathrm{~cm}^{-1}\left(I_{\mathrm{IR}}=74.9 \mathrm{~km} / \mathrm{mol}\right)$, which well reproduces the observed datum of $520 \mathrm{~cm}^{-1}$.

In the Raman spectra of selenophene and its perdeuterated isotopomer the $\mathrm{A}_{1}$ symmetry $\nu \mathrm{C}-\mathrm{H}$ and $\nu \mathrm{C}-\mathrm{D}$ vibrations (modes no. 1 and 2) are characterized by the highest $A_{\text {Raman }}$ values (Tables 2 and 3). As can be seen from Figures 5 and 6 , for wavenumbers $<1500 \mathrm{~cm}^{-1}$, the strongest Raman peak is placed at $1424 \mathrm{~cm}^{-1}\left(A_{\text {Raman }}=38.0 \AA^{4} / \mathrm{amu}\right)$ for 
TABLE 4: B3LYP/6-311G ${ }^{* *}$ first overtone wavenumbers $\left(\mathrm{cm}^{-1}\right)$ of selenophene isotopomers.

\begin{tabular}{|c|c|c|c|c|c|}
\hline \multirow{2}{*}{ Symm. } & \multirow{2}{*}{ Mode number ${ }^{\mathrm{a}}$} & \multicolumn{2}{|c|}{$\mathrm{C}_{4} \mathrm{H}_{4} \mathrm{Se}$} & \multicolumn{2}{|c|}{$\mathrm{C}_{4} \mathrm{D}_{4} \mathrm{Se}$} \\
\hline & & Harmonic & Anharmonic & Harmonic & Anharmonic \\
\hline \multirow{8}{*}{$\mathrm{A}_{1}$} & 1 & 6488 & 6185 & 4818 & 4646 \\
\hline & 2 & 6388 & 6092 & 4720 & 4544 \\
\hline & 3 & 2927 & 2840 & 2873 & 2799 \\
\hline & 4 & 2746 & 2690 & 2477 & 2434 \\
\hline & 5 & 2206 & 2185 & 1725 & 1696 \\
\hline & 6 & 2066 & 2029 & 1576 & 1563 \\
\hline & 7 & 1529 & 1503 & 1382 & 1364 \\
\hline & 8 & 919 & 907 & 892 & 883 \\
\hline \multirow{3}{*}{$\mathrm{A}_{2}$} & 9 & 1847 & 1821 & 1531 & 1515 \\
\hline & 10 & 1369 & 1363 & 1064 & 1055 \\
\hline & 11 & 1104 & 1095 & 946 & 938 \\
\hline \multirow{7}{*}{$\mathrm{B}_{1}$} & 12 & 6484 & 6178 & 4804 & 4645 \\
\hline & 13 & 6360 & 6060 & 4689 & 4503 \\
\hline & 14 & 3130 & 3044 & 3011 & 2943 \\
\hline & 15 & 2535 & 2484 & 2036 & 1986 \\
\hline & 16 & 2209 & 2183 & 1717 & 1697 \\
\hline & 17 & 1678 & 1658 & 1465 & 1454 \\
\hline & 18 & 1243 & 1214 & 1176 & 1150 \\
\hline \multirow{3}{*}{$\mathrm{B}_{2}$} & 19 & 1771 & 1750 & 1388 & 1374 \\
\hline & 20 & 1413 & 1407 & 1050 & 1045 \\
\hline & 21 & 802 & 794 & 733 & 726 \\
\hline
\end{tabular}

${ }^{\mathrm{a}}$ See Tables 2 and 3 for the mode description.

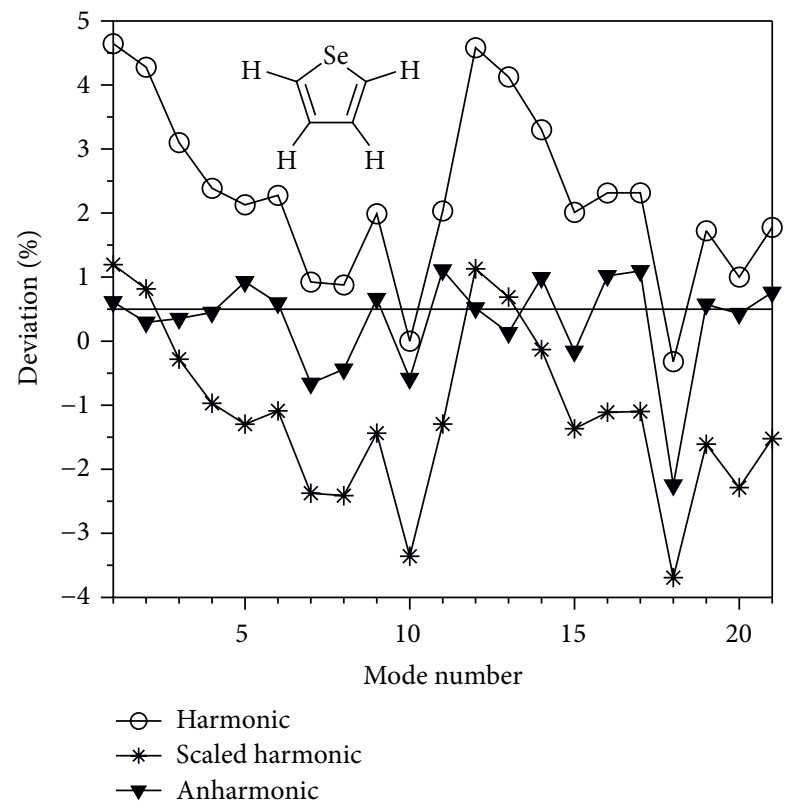

FIgURe 2: Percentage deviation relative to experiment [21] of the B3LYP/6-311G ${ }^{* *}$ wavenumbers of $\mathrm{C}_{4} \mathrm{H}_{4} \mathrm{Se}$.

$\mathrm{C}_{4} \mathrm{H}_{4}$ Se and at $1403 \mathrm{~cm}^{-1}\left(A_{\text {Raman }}=40.4 \AA^{4} / \mathrm{amu}\right)$ for $\mathrm{C}_{4} \mathrm{D}_{4} \mathrm{Se}$. This vibrational transition (mode no. 3 ) is mainly assigned to the $\mathrm{C}=\mathrm{C}+\mathrm{C}-\mathrm{C}$ bonds stretching with the

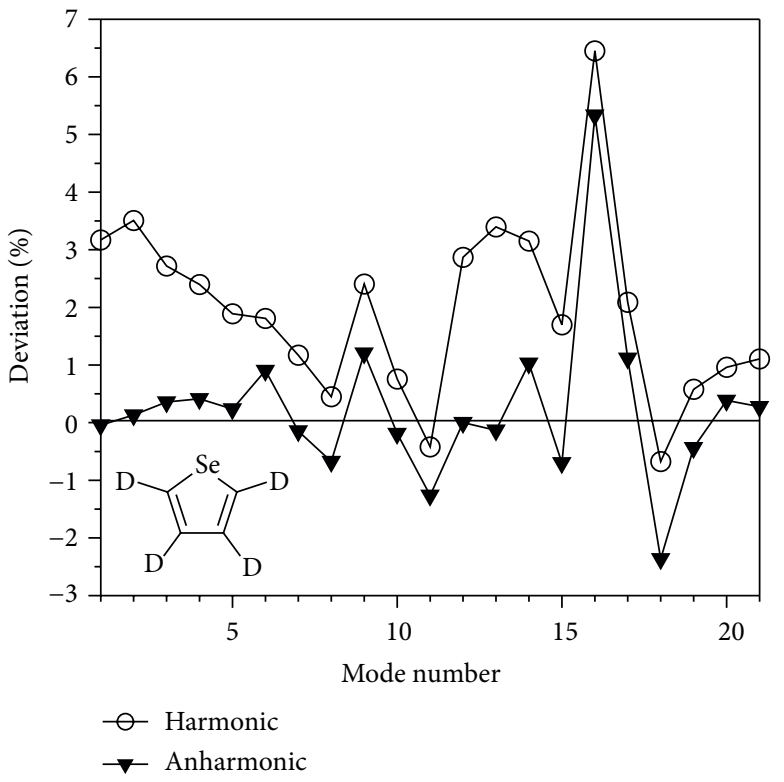

FIGURE 3: Percentage deviation relative to experiment [22, 23] of the B3LYP/6-311G** wavenumbers of $\mathrm{C}_{4} \mathrm{D}_{4} \mathrm{Se}$.

nonnegligible contribution from the in-plane C-H (C-D) bending motions. The abovecalculated wavenumbers can be compared with the experimental values of $1419 \mathrm{~cm}^{-1}(+0.4 \%)$ and $1398 \mathrm{~cm}^{-1}(+0.4 \%)$, respectively. 


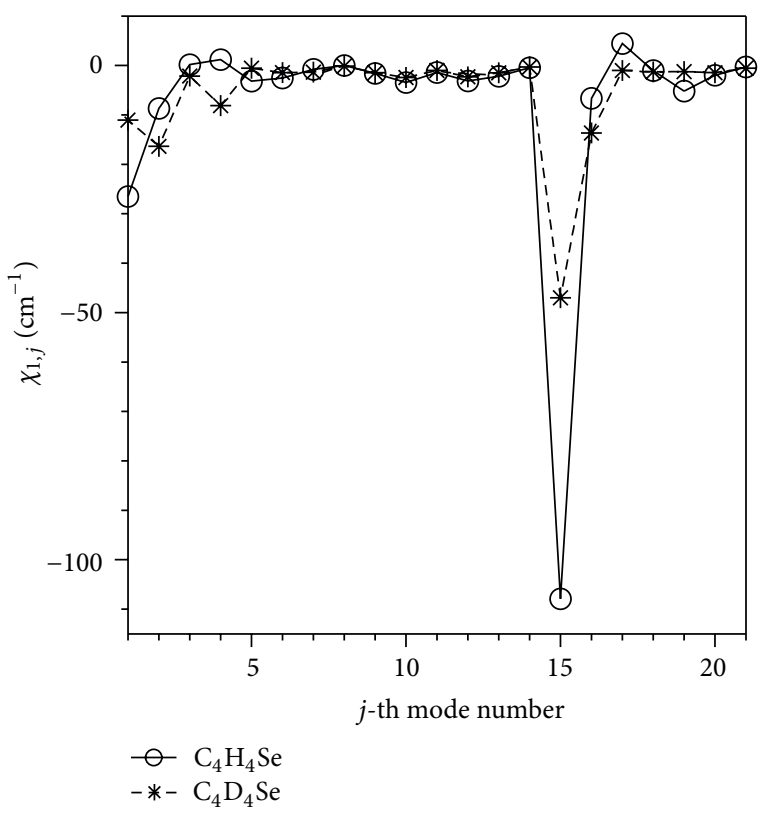

FIgURE 4: Anharmonic vibrational constants for the $\mathrm{C}-\mathrm{H}$ stretching mode no. 1 with the vibrational modes $\left(\chi_{1, j}, j=1-21\right)$ of $\mathrm{C}_{4} \mathrm{H}_{4} \mathrm{Se}$ and $\mathrm{C}_{4} \mathrm{D}_{4} \mathrm{Se}$. B3LYP/6-311G ${ }^{* *}$ results. For the mode numbering see Tables 2 and 3.

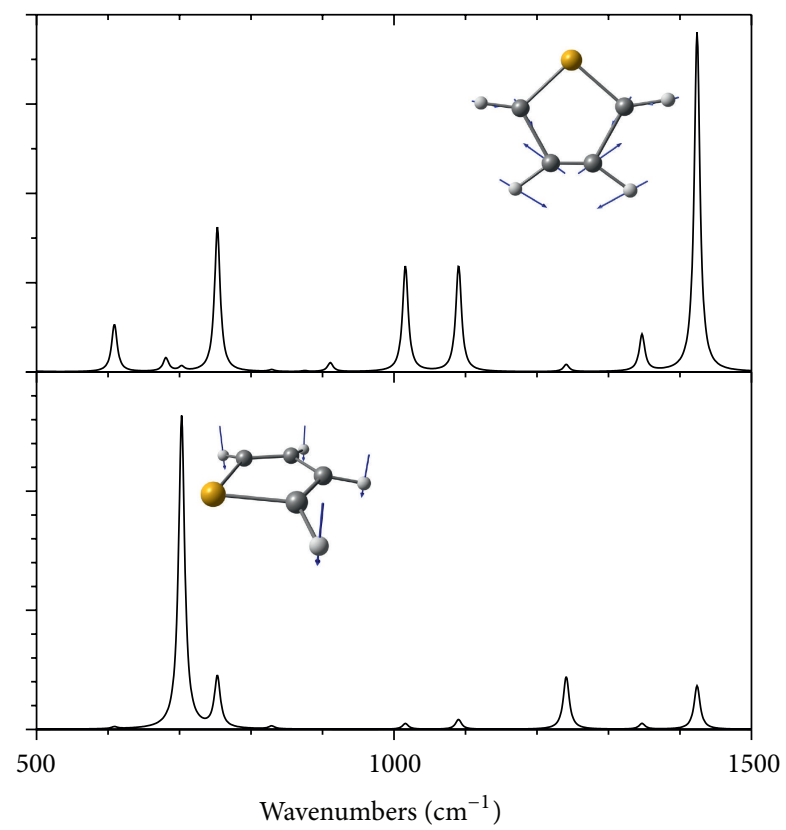

FIgURE 5: B3LYP/6-311G ${ }^{* *}$ anharmonic IR (bottom) and Raman (top) spectra of $\mathrm{C}_{4} \mathrm{H}_{4} \mathrm{Se}$ in the $500-1500 \mathrm{~cm}^{-1}$ wavenumber range. Lorentz line shapes with half-width of $10 \mathrm{~cm}^{-1}$ were used.

In Figure 7 we compare the computed (harmonic and anharmonic) and experimental $\mathrm{H} / \mathrm{D}$ isotopic wavenumber shifts for all the $\nu \mathrm{C}-\mathrm{H}$ vibrations (modes 1, 2, 12, and 13). Following the experimental results, upon deuteration the $\nu \mathrm{C}-\mathrm{H}$ wavenumbers are downward shifted by $765-787 \mathrm{~cm}^{-1}$. Under the harmonic approximation the $\nu \mathrm{C}-\mathrm{H}-\nu \mathrm{C}-\mathrm{D}$ wavenumber

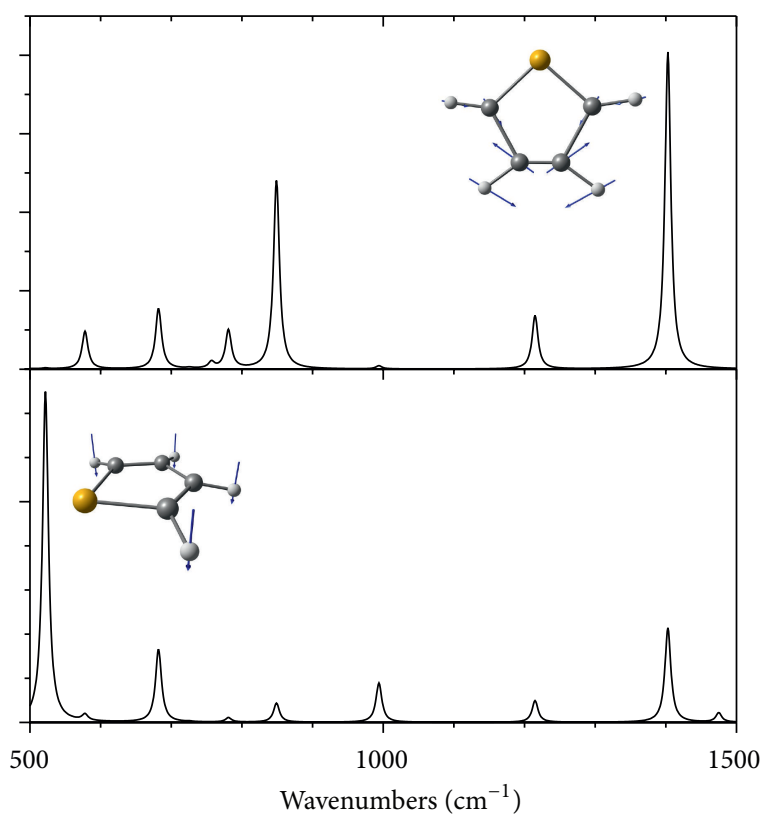

Figure 6: B3LYP/6-311G ${ }^{* *}$ anharmonic IR (bottom) and Raman (top) spectra of $\mathrm{C}_{4} \mathrm{D}_{4} \mathrm{Se}$ in the $500-1500 \mathrm{~cm}^{-1}$ wavenumber range. Lorentz line shapes with half-width of $10 \mathrm{~cm}^{-1}$ were used.

shifts are calculated to be in the $834-840 \mathrm{~cm}^{-1}$ wavenumber range, overestimating the observed shifts by $50-75 \mathrm{~cm}^{-1}(6-$ $10 \%)$. The introduction of the anharmonic corrections noticeably improves the accordance with experiment within 6$20 \mathrm{~cm}^{-1}(1-3 \%)$. For the remaining vibrations the magnitudes of the anharmonic corrections for the H/D isotopic shifts are little relevant.

Table 4 lists the wavenumber values for the overtone transitions of $\mathrm{C}_{4} \mathrm{H}_{4}$ Se and $\mathrm{C}_{4} \mathrm{D}_{4}$ Se here calculated under the harmonic and anharmonic treatments. Similarly to the results of the fundamental wavenumbers, the largest anharmonic effects are found for the $\nu \mathrm{C}-\mathrm{H}(\nu \mathrm{C}-\mathrm{D})$ vibrations, with the harmonic data being decreased by $5 \%$ (3-4\%).

\section{Conclusions}

The gas-phase equilibrium structure and harmonic and anharmonic IR and Raman spectra of selenophene and of its perdeuterated isotopomer have been determined and analyzed at the B3LYP/6-311G ${ }^{* *}$ level of theory. The overtone transitions have been here computed under the harmonic and anharmonic procedures. On the whole the harmonic wavenumbers overestimate the experimental data of the fundamental transitions with an rms deviation of $63 \mathrm{~cm}^{-1}$ for $\mathrm{C}_{4} \mathrm{H}_{4} \mathrm{Se}$ and $38 \mathrm{~cm}^{-1}$ for $\mathrm{C}_{4} \mathrm{D}_{4} \mathrm{Se}$. The corresponding rms deviations for the anharmonic calculations are reduced to 9 and $11 \mathrm{~cm}^{-1}$, respectively. In particular, the $\mathrm{C}-\mathrm{H}$ and $\mathrm{C}-\mathrm{D}$ stretches are strongly affected by the anharmonic corrections, which reproduce the experimental H/D isotopic frequency shifts within $6-20 \mathrm{~cm}^{-1}(1-3 \%)$. The present results suggest that the anharmonic PT2 scheme in combination with the B3LYP functional and the $6-311 \mathrm{G}^{* *}$ basis set can be 


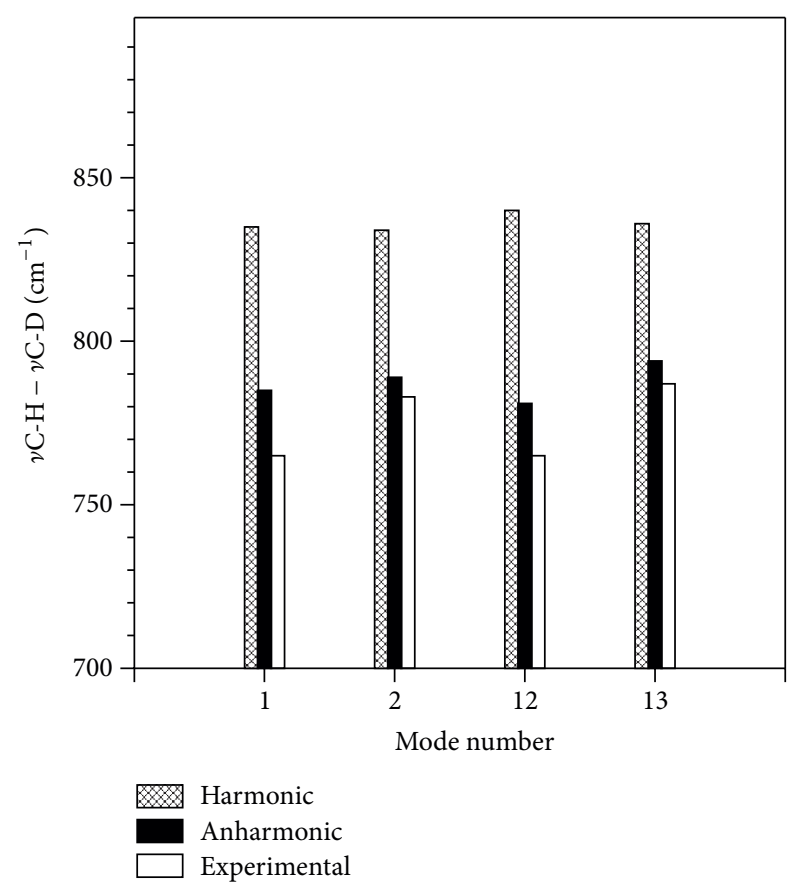

FIGURE 7: H/D isotopic wavenumber shifts for the $\mathrm{C}-\mathrm{H}$ stretching modes between $\mathrm{C}_{4} \mathrm{H}_{4}$ Se and $\mathrm{C}_{4} \mathrm{D}_{4} \mathrm{Se}$. Comparison between experimental [21-23], harmonic, and anharmonic B3LYP/6-311G** data.

considered a promising method to calculate the vibrational spectra of cyclic compounds for which observed data are incomplete or not yet available in the literature.

\section{References}

[1] W. J. Hehre, L. Random, P. v. R. Schleyer, and J. A. Pople, Ab Initio Molecular Orbital Theory, Wiley, New York, NY, USA, 1986.

[2] P. Pulay, G. Fogarasi, G. Pongor, J. E. Boggs, and A. Vargha, "Combination of theoretical ab initio and experimental information to obtain reliable harmonic force constants. Scaled Quantum Mechanical (SQM) force fields for glyoxal, acrolein, butadiene, formaldehyde, and ethylene," Journal of the American Chemical Society, vol. 105, no. 24, pp. 7037-7047, 1983.

[3] G. Rauhut and P. Pulay, "Transferable scaling factors for density functional derived vibrational force fields," Journal of Physical Chemistry, vol. 99, no. 10, pp. 3093-3100, 1995.

[4] D. A. Clabo Jr., W. D. Allen, R. B. Remington, Y. Yamaguchi, and H. F. Schaefer III, "A systematic study of molecular vibrational anharmonicity and vibration-rotation interaction by self-consistent-field higher-derivative methods. Asymmetric top molecules," Chemical Physics, vol. 123, no. 2, pp. 187-239, 1988.

[5] W. Schneider and W. Thiel, "Anharmonic force fields from analytic second derivatives: method and application to methyl bromide," Chemical Physics Letters, vol. 157, no. 4, pp. 367-373, 1989.

[6] V. Barone, "Anharmonic vibrational properties by a fully automated second-order perturbative approach," Journal of Chemical Physics, vol. 122, no. 1, Article ID 014108, 21 pages, 2005.
[7] J. M. Bowman, "Self-consistent field energies and wavefunctions for coupled oscillators," The Journal of Chemical Physics, vol. 68, no. 2, pp. 608-610, 1978.

[8] G. M. Chaban, R. B. Gerber, and K. C. Janda, "Transition from hydrogen bonding to ionization in $(\mathrm{HCl})_{n}\left(\mathrm{NH}_{3}\right)_{n}$ and $(\mathrm{HCl})_{n}\left(\mathrm{H}_{2} \mathrm{O}\right)_{n}$ clusters: consequences for anharmonic vibrational spectroscopy," Journal of Physical Chemistry A, vol. 105, no. 36, pp. 8323-8332, 2001.

[9] O. Bludský, J. Chocholoušová, J. Vacek, F. Huisken, and P. Hobza, "Anharmonic treatment of the lowest-energy conformers of glycine: a theoretical study," Journal of Chemical Physics, vol. 113, no. 11, pp. 4629-4635, 2000.

[10] R. Burcl, N. C. Handy, and S. Carter, "Vibrational spectra of furan, pyrrole, and thiophene from a density functional theory anharmonic force field," Spectrochimica Acta A, vol. 59, no. 8, pp. 1881-1893, 2003.

[11] N. C. Handy and A. Willetts, "Anharmonic constants for benzene," Spectrochimica Acta A, vol. 53, no. 8, pp. 1169-1177, 1997.

[12] V. Barone, "Accurate vibrational spectra of large molecules by density functional computations beyond the harmonic approximation: the case of azabenzenes," Journal of Physical Chemistry A, vol. 108, no. 18, pp. 4146-4150, 2004.

[13] V. Barone, "Vibrational spectra of large molecules by density functional computations beyond the harmonic approximation: the case of pyrrole and furan," Chemical Physics Letters, vol. 383, no. 5-6, pp. 528-532, 2004.

[14] V. Barone, G. Festa, A. Grandi, N. Rega, and N. Sanna, "Accurate vibrational spectra of large molecules by density functional computations beyond the harmonic approximation: the case of uracil and 2-thiouracil," Chemical Physics Letters, vol. 388, no. 4-6, pp. 279-283, 2004.

[15] A. D. Boese and J. M. L. Martin, "Vibrational spectra of the azabenzenes revisited: anharmonic force fields," Journal of Physical Chemistry A, vol. 108, no. 15, pp. 3085-3096, 2004.

[16] V. Librando, A. Alparone, and Z. Minniti, "Computational note on anharmonic infrared spectrum of naphthalene," Journal of Molecular Structure: THEOCHEM, vol. 847, no. 1-3, pp. 23-24, 2007.

[17] A. Alparone, "Ab initio and DFT anharmonic spectroscopic investigation of 1,3-cyclopentadiene," Chemical Physics, vol. 327, no. 1, pp. 127-136, 2006.

[18] M. J. Frisch, G. W. Trucks, H. B. Schlegel et al., GAUSSIAN 09, Revision A. 02, Gaussian, Wallingford, UK, 2009.

[19] A. Poletti, R. Cataliotti, and G. Paliani, "Infrared crystal spectra of heterocyclic compounds. II. IR spectrum of selenophene in the solid state," Chemical Physics, vol. 5, no. 2, pp. 291-297, 1974.

[20] R. Cataliotti and G. Paliani, "Infrared study of the C-H stretching region of five-membered heterocyclic compounds," Canadian Journal of Chemistry, vol. 54, pp. 2451-2457, 1976.

[21] G. Paliani, R. Cataliotti, A. Poletti, F. Fringuelli, A. Taticchi, and M. G. Giorgini, "Vibrational analysis of tellurophene and its deuterated derivatives," Spectrochimica Acta A, vol. 32, no. 5, pp. 1089-1104, 1976.

[22] A. Santucci, G. Paliani, and R. S. Cataliotti, "Force field calculation of the in-plane fundamental motions of tellurophene and selenophene," Spectrochimica Acta A, vol. 41, no. 5, pp. 679-685, 1985.

[23] A. Santucci, G. Paliani, and R. S. Cataliotti, "Force field calculation of the out-of-plane fundamental modes of tellurophene and selenophene," Chemical Physics Letters, vol. 138, no. 2-3, pp. 244-249, 1987. 
[24] J. S. Kwiatkowski, J. Leszczyński, and I. Teca, "Molecular structure and infrared spectra of furan, thiophene, selenophene and their 2,5-N and 3,4- $\mathrm{N}$ derivatives: density functional theory and conventional post-Hartree-Fock MP2 studies," Journal of Molecular Structure, vol. 436-437, pp. 451-480, 1997.

[25] A. A. El-Azhary and A. A. Al-Kahtani, "Force field scale factors of effective core potential basis sets of some selenium and tellurium heterocyclic molecules, selenophene, 1,2,5selenadiazole, tellurophene and 1,2,5-telluradiazole," Journal of Molecular Structure: THEOCHEM, vol. 572, pp. 81-87, 2001.

[26] T. Kupka, R. Wrzalik, G. Pasterna, and K. Pasterny, "Theoretical DFT and experimental Raman and NMR studies on thiophene, 3-methylthiophene and selenophene," Journal of Molecular Structure, vol. 616, no. 1-3, pp. 17-32, 2002.

[27] S. Millefiori and A. Alparone, "Theoretical determination of the vibrational and electronic (hyper)polarizabilities of $\mathrm{C}_{4} \mathrm{H}_{4} \mathrm{X}$ (X=O, S, Se, Te) heterocycles," Physical Chemistry Chemical Physics, vol. 2, no. 11, pp. 2495-2501, 2000.

[28] A. D. Becke, "A new mixing of Hartree-Fock and local densityfunctional theories," The Journal of Chemical Physics, vol. 98, no. 2, pp. 1372-1377, 1993.

[29] C. Lee, W. Yang, and R. G. Parr, "Development of the ColleSalvetti correlation-energy formula into a functional of the electron density," Physical Review B, vol. 37, no. 2, pp. 785-789, 1988.

[30] S. Millefiori and A. Alparone, "(Hyper)polarizability of chalcogenophenes $\mathrm{C}_{4} \mathrm{H}_{4} \mathrm{X}(\mathrm{X}=\mathrm{O}, \mathrm{S}, \mathrm{Se}, \mathrm{Te})$ conventional ab initio and density functional theory study," Journal of Molecular Structure: THEOCHEM, vol. 431, no. 1-2, pp. 59-78, 1998.

[31] S. Millefiori and A. Alparone, "Second hyperpolarisability of furan homologues $\mathrm{C}_{4} \mathrm{H}_{4} \mathrm{X}(\mathrm{X}=\mathrm{O}, \mathrm{S}, \mathrm{Se}, \mathrm{Te})$ : $\mathrm{ab}$ initio $\mathrm{HF}$ and DFT study," Chemical Physics Letters, vol. 332, no. 1-2, pp. 175$180,2000$.

[32] K. Kamada, T. Sugino, M. Ueda, K. Tawa, Y. Shimizu, and K. Ohta, "Femtosecond optical Kerr study of heavy-atom effects on the third-order optical non-linearity of thiophene homologues: electronic hyperpolarizability of tellurophene," Chemical Physics Letters, vol. 302, no. 5-6, pp. 615-620, 1999.

[33] K. Kamada, M. Ueda, H. Nagao et al., "Molecular design for organic nonlinear optics: polarizability and hyperpolarizabilities of furan homologues investigated by ab initio molecular orbital method," Journal of Physical Chemistry A, vol. 104, no. 20, pp. 4723-4734, 2000.

[34] B. Jansik, B. Schimmelpfennig, P. Norman, P. Macak, H. Ågren, and K. Ohta, "Relativistic effects on linear and non-linear polarizabilities of the furan homologues," Journal of Molecular Structure: THEOCHEM, vol. 633, no. 2-3, pp. 237-246, 2003.

[35] R. D. Brown, F. R. Burden, and P. D. Godfrey, "The microwave spectrum of selenophene," Journal of Molecular Spectroscopy, vol. 25, no. 4, pp. 415-421, 1968.

[36] K. K. Irikura, R. D. Johnson III, and R. N. Kacker, "Uncertainties in scaling factors for ab initio vibrational frequencies," Journal of Physical Chemistry A, vol. 109, no. 37, pp. 8430-8437, 2005.

[37] G. A. Zhurko and D. A. Zhurko, Chemcraft, http://www.chemcraftprog.com. 

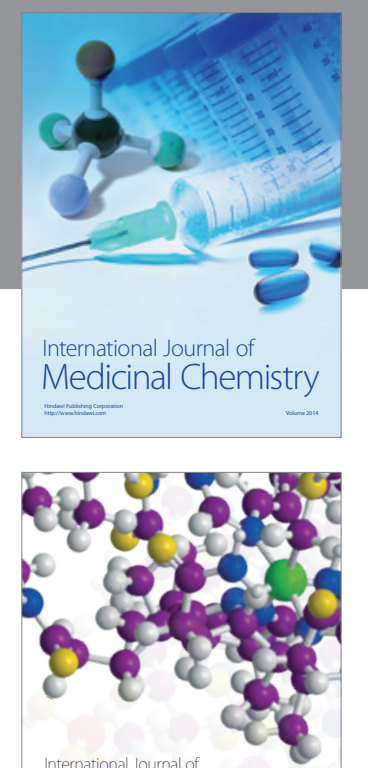

\section{Carbohydrate} Chemistry

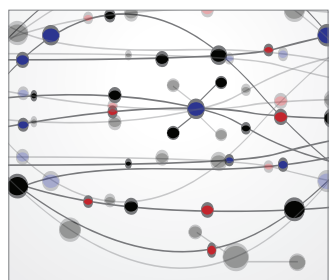

The Scientific World Journal
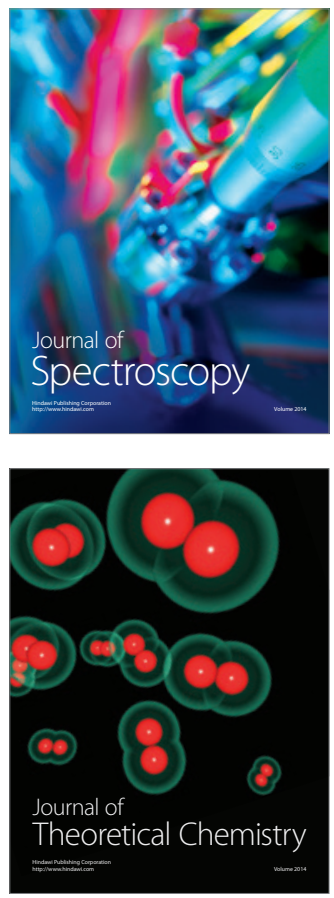
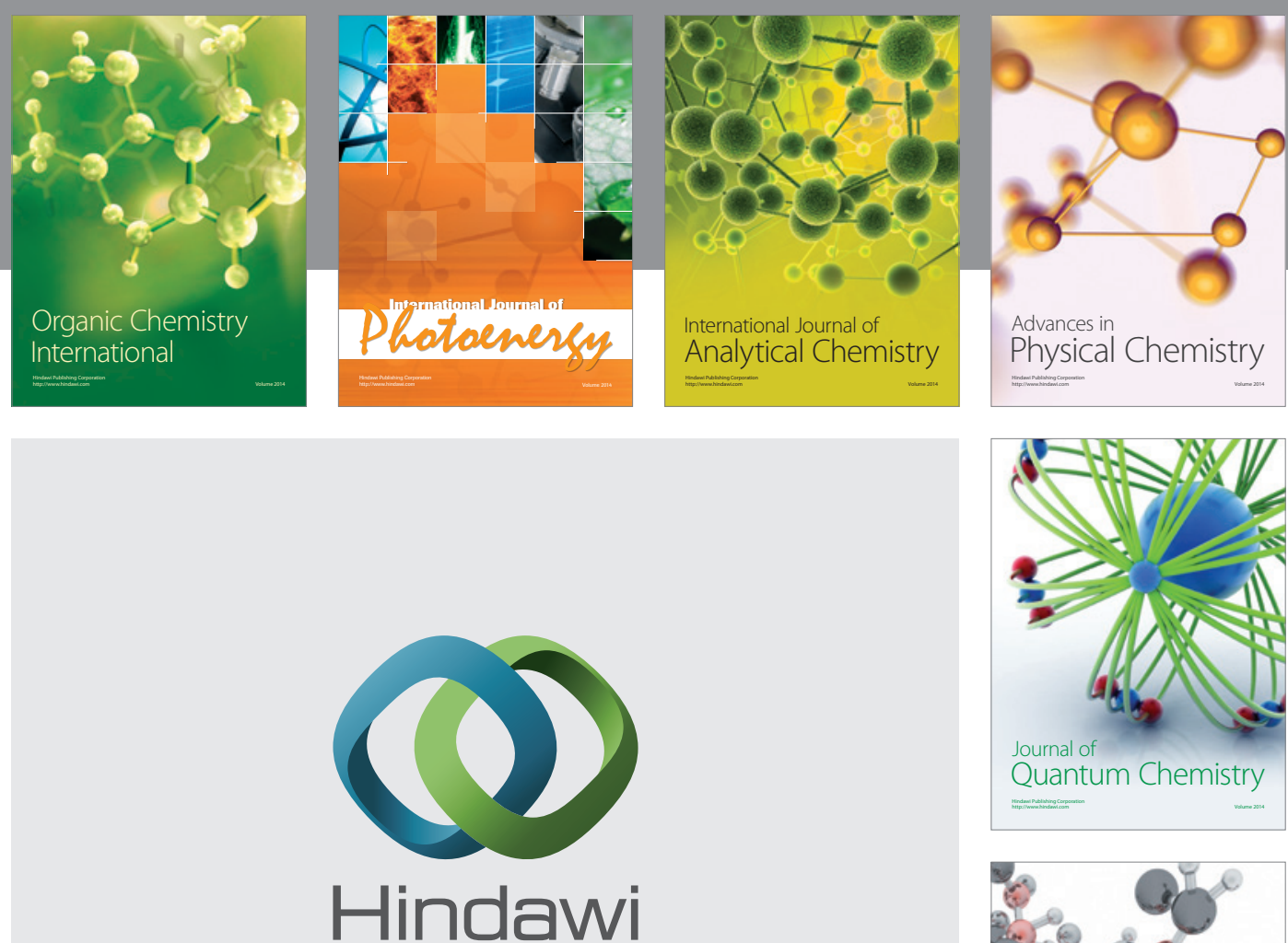

Submit your manuscripts at

http://www.hindawi.com

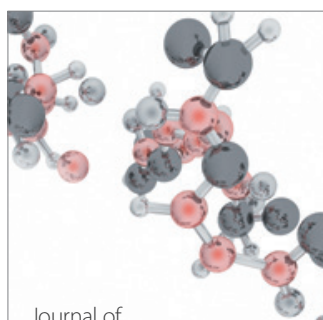

Analytical Methods

in Chemistry

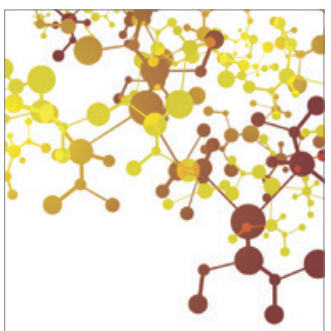

Journal of

Applied Chemistry

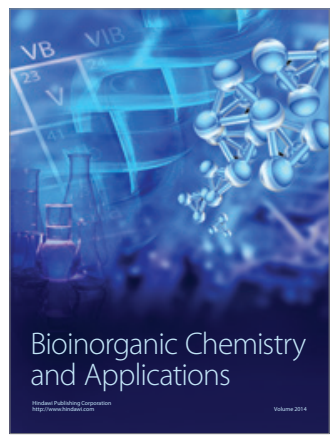

Inorganic Chemistry
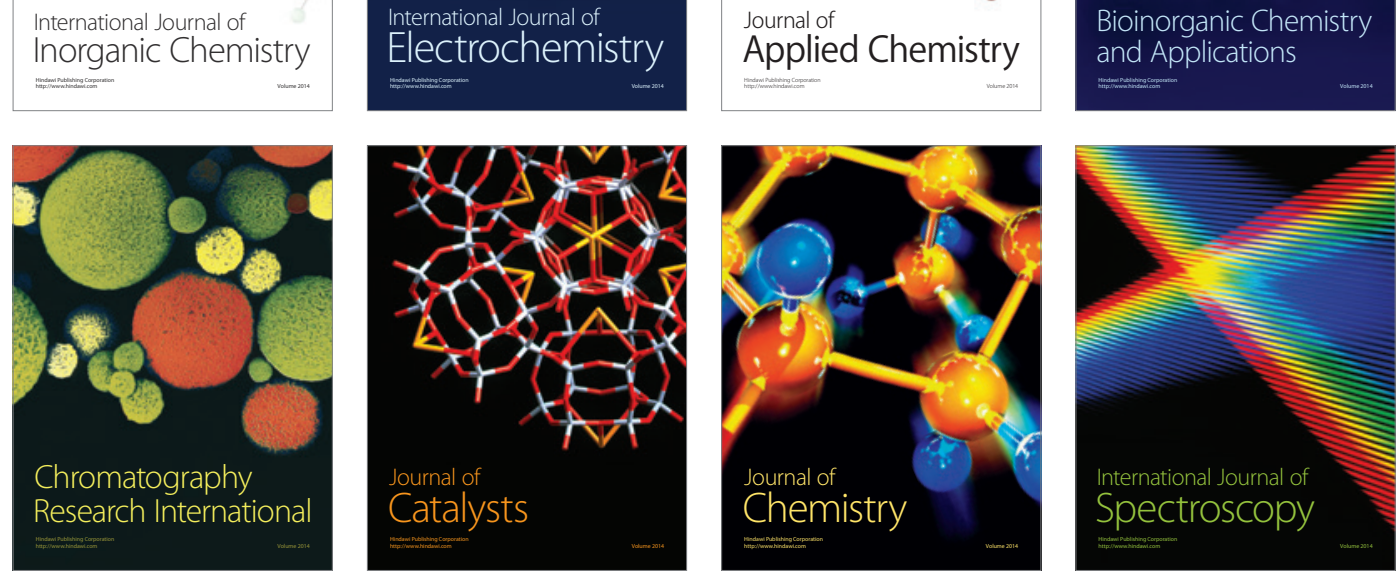